\title{
Functionality Assessment and Requirements of the IT System in an Education Institution
}

\author{
Ljiljana Ruzic-Dimitrijevic \\ Higher Education Technical \\ Schoolof Professional Studies, \\ Novi Sad,Serbia \\ Email: ljdimitrijevic@gmail.com
}

\author{
Milorad Stevic \\ Higher Education Technical \\ School of Professional Studies, \\ Novi Sad, Serbia \\ Email: milorad.stevic@live.com
}

\begin{abstract}
The information technology (IT) system in one higher education institution which serves as a support to many processes, with special accent on teaching process is described in this paper. The objective of the paper is to underline the significance of the IT system for an education institution as well as the required changes in this system due to the implementation of "Bologna" study rules. Apart from description of the system and advantages allowed by this system, difficulties and problems which occur in further development and maintaining of this system are indicated
\end{abstract}

\section{INTRODUCTION}

$\mathrm{E}$ ACH company has many resources important for its business. Today, the information system has become very important and irreplaceable resource for successful business operation and management. IT (information technology) is a strategic resource. Managers have to be involved in design of information system [1]. The IT system of a higher education institution is particularly important. It must be used as integral part of all processes of this institution: teaching, enrolment, finances, administration, marketing, researches etc.

New study rules, resulting from "Bologna" system, have brought a lot of positive moving toward a much better quality in the teaching process and its outcomes. In order to achieve the goals of Bologna, the teaching staff had to raise the awareness about the using of new contemporary educational methods and on the important role IT takes in it.

In this paper, we will focus only on the part in relation to the teaching, from the students' side, as well as from the side of the teaching staff. With our transition to the "Bologna" curricula and syllabi [2] and with changes in the Law on higher education [3], it was necessary to introduce new categories in managing the higher education institution [4]. One of the important items is completely new information system which can follow the teaching and studying processes by the new rules.

The emergence of this IS is represented in the papers [5] and [6], while this paper will try to assess the implementation of that system and its contribution to the more efficient teaching process, greater success of the students, as well as mutual satisfaction of the users (administrative staff, teachers and students).

We will stress the way of developing the IT system and advantages of such an approach. Our goal in this paper is not to investigate project designing of the information system, but to point out its importance and benefits in educational processes. In addition, we will mention some problems regarding the system maintenance.

Development of IS was launched by the IT professors engaging several advanced students in their final study year. Over time, the IT team of students at specialist studies was formed, and led by the assistant, who was on the postgraduate studies IT and who, by his enthusiasm and practical experience, transferred to advanced students, succeeded to create atmosphere where the mere entrance into his team [7] represented the matter of prestige.

The thing we need to point out as the advantage of this working method is firstly the fact that the software is developed by the teaching staff. Considering all processes and their connection, with continual consultation with the staff of student service, the managing structure was directing and coordinating development of the system [6]. The implementation of the new study rules through IS improved understanding and accepting of the new rules by the teachers and staff.

Thanks to this working method, our school is most likely has made the greatest step forward in following the new rules of studies "according to Bologna" in Serbia.

Since the IT team in charge for developing the system is consisted of students and the teaching staff, it means that all of them are participants in the processes and that they have deeper insight in them and have greater knowledge on their requirements than certain software houses, which produce typical software, often with many unnecessary elements, and without possibility for efficient use of certain necessary functions specific for the individual company.

On the other side, insufficiencies of such work can be seen exactly in a composition of the team, which is variable, because students mainly leave the school after graduation and the team gets the new students all the time, but they start to work on the system which is already developed. 


\section{II.FUNCTIONALITY ANALYSIS}

The risk assessment has become a very current and important for successful business as well as for successful realization of a project.

The risk of our project can be particularly analyzed. Different methods of risk assessment can be used, but what has become the fact proven in practice, it is that the new IS has mitigated and speeded up the work for the teaching staff of the School, students meet their requirements far more easier, and the teachers carry out their obligation with higher quality.

In order to gain deeper insight in the area of IS (information system) implementation in the School, we need to consider all processes which are carried out within that institution. We will focus only on the teaching processes [6]:

- Students' enrolment of the school year with registering of subjects in each semester

- Teaching

- Students assessing during tuition delivery and exams

- Tuition fee charges

- Issuing of certificates, degrees and students record

Each of these processes is included in the information system. Upon students' enrolment, the student's record is created so the student can access to it over the Internet and see its content with all data relevant for his activities. Students can register for the exams and subject they want to attend by online system. Their record contains all data about previously passed exams, payments, debts, as well as about improvement during semester for each subject and points they win after fulfilling pre-exam obligations. There are no previous crowds and a long line of people in front of office any more.

\section{Rudan (Goran) Aleksandra IT6/12 $\times$ 国}

\begin{tabular}{|c|c|c|c|c|c|c|}
\hline $\begin{array}{lll}\text { Nastava } & \text { Položeni ispiti } & \text { Ispitni } \\
\end{array}$ & i rokovi & \begin{tabular}{ll|l} 
Studentski račun & Obračunske grupe & Over
\end{tabular} & iemestara & & & \\
\hline Prijavljeni predmeti & semestar & \multirow{2}{*}{$\begin{array}{l}\text { Dezbednost informacionih sistema } \\
\text { Siffa: } 05270 \\
\text { ESPB: }: 6.0\end{array}$} & \multicolumn{4}{|c|}{ Kadar: } \\
\hline Elektrotehnika 1 & Zimski & & \multicolumn{4}{|c|}{$\begin{array}{l}\text { Ljijjana } \\
\text {-Asistent: dipl ing Stević Milorad }\end{array}$} \\
\hline Internet jezici i alati 1 & Zimski & \multirow{3}{*}{$\begin{array}{l}\text { Fond predavanja: } 3 \\
\text { Fond vežbi: } 2 \\
\text { Blok nastava: NE } \\
\text { Izborni predmet: NE }\end{array}$} & \multicolumn{4}{|c|}{$\begin{array}{l}\text {-Asistent: dipl.ing Stević Milorad } \\
\text {-Asistent: ing Danić Miroslav }\end{array}$} \\
\hline Računarske mreže & Zimski & & & & & \\
\hline Strukture baze podataka & Zimski & & & & & \\
\hline Ekonomika i organizacija predı & , Zimski & Naziv & Vrsta & Osvojeno & Max & Min \\
\hline \multirow{2}{*}{$\begin{array}{c}\text { Bezbednost informacionih siste } L \\
\text { Druga godina }\end{array}$} & E Letnji & Zaštita podataka i standardi & kol & 0 & 20.0 & 12.0 \\
\hline & & Malware & kol & 12.5 & 20.0 & 10.0 \\
\hline Internet jezici i alati 2 & Letnji & Procena rizika & kol & 0 & 20.0 & 10.0 \\
\hline Mikroračunarski sistemi & Letnji & Malware II & kol & 0 & 30.0 & 15.0 \\
\hline Primenjene baze podataka & Letnji & Projektni zadatak & pro & 0 & 10.0 & 6.0 \\
\hline Multimedija 1 & Letnji & & & & & \\
\hline
\end{tabular}

Fig. 1 Student's record - pre-exam obligations

Work of the student service is far more efficient, the possibilities for mistakes are much lesser and easier to notice, because of possibility for both monitoring of students activities, on one side, and activities of administration, on the other side, by simple access to the data in system. Relationship with students is free from tension and misunderstanding in that way. The newest function developed in this system is creating of diploma supplement, which has been done separately till now and requested special engagement of the staff of student service with great probability for mistakes, and that is the reason for all previous multiple verifications.

At first glance, teaching staff may have gained more obligations because of the new system for monitoring of students' work and their grading during entire semester, and not only on exam at the end of teaching. This system introduces an order and reduces subjectivity in grading.

The teacher must give clear rules of working on his subject and regularly and precisely fill in pre-exam obligations which student fulfills. In that way, the final grade will be more realistic and reflect student's work during entire semester. The teacher can simply communicate with the students registered for listening of the subject, by generating group mail via e-mail.

The system is posted on the school intranet and teachers have access from their own cabinet computers. For now, access over the Internet is offered only to a few teachers, although it would be more comfortable to have possibility for access out of the intranet in the school. The main reason is insecurity of user in terms of unawareness of the importance of protection, but it is a part of the future plan when condition for the higher level of security will be present.

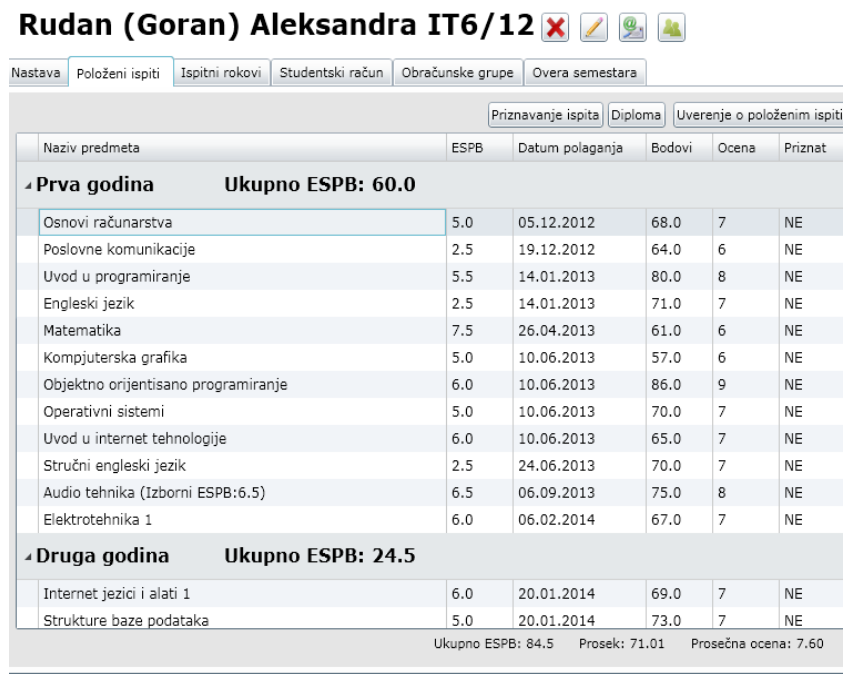

Fig. 2 Student's record - exam results

What is particularly useful for the teaching process, apart from introducing pre-exam obligations for the students and monitoring of their work, is statistical review of pass-rate of students which every teacher can generate for his own subjects. These data are extremely useful for the analysis of the teachers work and their self-evaluation. The percent of students which fulfill their obligations and pass exam represent special indicators. By analysis of these data, the teacher can estimate if the pre-exam obligations are too easy to be done, if great number of students fulfill pre-exam obligations and considerably smaller number of students pass exam, as well as if they are too hard, if very small number of students fulfill the obligations and don't have right even to take the exam. By constant correction, teacher can improve quality of his work. 
Besides, in order to achieve even better results, the teacher will also do his best to give good lectures and teaching material to his students, so they can become more successful. Distance learning system which is used in certain programs opens possibility for the teachers to use hybrid system posting the teaching material online and asking the students to get introduce with it before lecture.

The open source software is used in this part, but the idea for developing our own software emerges within our project, which would support distance learning system and grading fulfilling the characteristics of our teaching system.

\section{ARCHITECTURE OF INFORMATION SYSTEM}

The Information system of the Higher Education Technical School of Professional Studies in Novi Sad is projected and realized as multilayer, service oriented architecture. The classical layers can be identified in the architecture: the data management layer, service layer with realized web services and client layer with realized client interface.

Each of these layers keeps on to decompose further, so that the data management layer contains a relational database management system, that is to say, system for the structured data management and system for the unstructured data management; the service layer contains two layers within itself - one for accepting and realization of requirement for manipulation over the structured data and one for accepting and realization of requirement for manipulation over unstructured data, while client interface for the access by PC computer is developed on the client side, but client interface is developed also for the access to the system over the new generation devices - smart phones and tablets.

In this way described multilayer service oriented architecture is shown in Table 1 . The data management layer takes care of two types of data which are stored in the information system, structured and unstructured data.

For the first one, it is characteristic to have database scheme and this type of data is modeled by relational language for description and data management based on first-order predicate logic. Practical implementation is carried out using Microsoft SQL Server system for the relational database management system.

For the second type of data, it is characteristic that they don't have database scheme while management system for these data is relied on new type of system for the unstructured data management-NoSQL. Practical implementation is carried out by MongoDB system for the unstructured data management.

A special attention is dedicated to the binary files, because it is hard to predict capacities for storing such type of data, and because of unpredictability of their number, structure and size; and that's why horizontal scalability of the system for the binary files management is so important.

For the practical implementation, the same platform as for the unstructured data is used, Mongo DB database, because this platform has special specification intended for these structures-GrisFS management. This specification is suitable for practical implementation because of the feature such as a secure horizontal scalability, tolerance on interrupted work of projected number of servers, as well as optimization of server load used in the system.

Service layer is divided in accordance to division which is also carried out on layer for data management, on service layer which deals with manipulation over structured data, and on service layer that deals with manipulation over unstructured data. Practical implementation of the first service layer is carried by use of .NET technology and C\# programming language. By using of these technologies, the services based on SOAP protocol were developed, and their purpose is to, on the request of user over the client interface, carry out manipulation over structured data on a layer of data of the information system.

The second type of service is developed to serve for different application - to allow standardized manipulation over unstructured data. In accordance to that fact, technology and protocols used for this purpose are also different. Practical implementation of this service layer is carried out by using Python programming language and these services are based on a REST protocol which is more efficient for work with unstructured data and with greater number of data, which is useful in a case of manipulation over binary files. It is possible to carry out the manipulation over data stored in a SQL Server Database, but also in a MongoDB database from any service layer.

Client layer of the information system is developed according to expected users of the information system. The most frequent users are users who use PC computers in order to realize interaction with the information system and for these users the application based on C\# programming language and Silver light/Pipelight technology is developed. 


\begin{tabular}{|l|l|l|l|}
\hline \multicolumn{5}{|c|}{ TABLE I. } \\
\hline Layer & Data type/Device type/Client & Practical implementation & Technology/OS \\
\hline Data management layer & SQL Server & RDBMS/Windows \\
\hline & Structured data & MongoDB & NoSQL/Linux \\
\hline & Unstructured data and binary files & C\# & SOAP/Windows \\
\hline Service layer & \multicolumn{5}{|c|}{ Structured data } & REST/Linux \\
\hline & Unstructured data and binary files & Python & .NET/Plugin \\
\hline
\end{tabular}

The number of second group of users is also growing, and these are the users of smart devices, phones and tablets, who need to establish interaction with information system. For these users, different type of user interface is developed, practically realized by using AngularJS programming language and HTML technology. As in the case of service layer, it is possible to realize communication with both service layers from any client interface.

\section{PROTECTION OF THE INFORMATION SYSTEM}

The information system is projected and realized in such a way to offer high level of data protection. Data protection is carried out on levels which are the subject of studying in literature: there is protection of data at rest, data in motion/data in transit and data in use. Protection of data at rest is carried out all the time.

Both databases use techniques of replication and creation of back up data at regular time intervals. Then, these copies are automatically copied on protected location. This part of protection is done due to potential physical damages on servers.

Protection of data in motion is done by using the encryption, that is to say, by using of https protocol.

Data in use are protected by projecting and realizing of the subsystem for approval to access to data, which present advanced technique of data access based on group of users.

Instead of this access, the access based on data classification on sensitive and less sensitive is used, as well as on the user account management in order to define precisely which data are accessible for each user.
It allows that only authorized users can manipulate data which are approved for manipulation. Such approach allows also efficient monitoring of user activities in the system because of later analysis of these activities and eventual identifying the misuse of data.

\section{THE PROBLEMS IN MAINTAINING AND FURTHER DEVELOPMENT OF THE INFORMATION SYSTEM}

Conceived and realized as the ultimate IT product, with respect for the most modern standards, rules and recommendations which exist in the world, the system has already been working for three years with very modest equipment without interruption, crash and security data violation. Apart from all previously mentioned, this information system is ill-equipped because of several problems:

Lack of regularly engaged engineers in maintaining and continual development

- Only one person is engaged in developing and maintaining of the information system all the time, but partly, and mostly in teaching activities and a few individuals more who are engaged occasionally, but partly on these tasks, with contracts which will expire in next several months

- Syndrome of concentrating all business activities in the organization on IT center, that is to say, syndrome of considering the information system as a whole which will individually adjust itself to the business needs of organization.

- Lack of open minds for the new ideas and business application in further development of the information system

- Unwillingness to accept the information system as very important product for the main activity of the 
organization, as a direct and indirect generator of financial gain for the organization.

\section{CONCLUSION}

The application of "Bologna" system in teaching and learning processes is very poor if there is no support of a suitable information system. Besides supporting these processes, the information system following Bologna curricula offers more quality work. Both teachers and students have to respect the required policy that is implemented in the information system and everything is transparent. The opportunity of electronic tracking of students' success provides a possibility of enhancing both teaching and learning

This paper describes the problems that may arise in the development and maintenance of the information system. However, it has helped us to have a better insight into all flows of information and required new commitments of teachers and student services regarding the supply and use of data. The increased concern about students and a better communication with them is just a small detail from an incredibly large contribution to their success in general.

\section{REFERENCES}

[1] B.Gates, Business @ the Speed of Thought,. Warner Books, Inc., New York, 2001

[2] The Bologna Declaration. (2000). On the European space for higher education: An explanation Retrieved November 9, 2012, from http://ec.europa.eu/education/policies/educ/bologna/bologna.pdf

[3] Zakon o visokom obrazovanju (Law on higher education), (2005). Službeni glasnik RS, (Official Gazette of Republic of Serbia) 76/2005, Belgrade, Serbia.

[4] J. Dakic, "Uloga i značaj menadžmenta u visokom obrazovanju" (The role and importance of management in higher education), SYMORG; XIII International Symposium Innovative management and business performance. 2012

[5] Z. Lovrekovic, L. Ruzic-Dimitrijevic, and B. Nikolic, "Information system implementation based on process approach at higher education institutions", Proceedings of the 2007 Computer Science and IT Education Conference, Mauritius,2007, pp. 454-461.

[6] L. Ruzic-Dimitrijevic, and B. Nikolic, "Designing and building an information system for a higher education institution", Proceedings of the Informing Science \& IT Education Conference 2008, Bulgaria, pp. 283-300.

[7] B.Nikolic, J. Dakic, L. Ruzic-Dimitrijevic, "Contemporary management in a higher education institution in Serbia", Online Journal of Applied Knowledge Management Volume 1, Issue 1, 2013 pp72-81 